\title{
Calcineurin Inhibitors in COVID-19: Lessons Learnt from Transplantation Medicine
}

\author{
René Hage $^{1,2 *}$, Carolin Steinack ${ }^{1,2}$ and Macé M Schuurmans ${ }^{1,2}$ \\ ${ }^{1}$ University Hospital Zurich, Division of Pulmonology, Switzerland \\ ${ }^{2}$ University of Zurich, Faculty of Medicine, Switzerland
}

*Corresponding author: René Hage, University Hospital Zurich, Division of Pulmonology, Faculty of Medicine, Switzerland

\begin{tabular}{|c|c|}
\hline ARTICLE INFO & ABSTRACT \\
\hline Received: 慧 July 25, 2020 & Citation: René Hage, Carolin Steinack, Macé M Schuurmans. Calcineurin Inhibitors in \\
\hline Published: August 10, 2020 & $\begin{array}{l}\text { COVID-19: Lessons Learnt from Transplantation Medicine. Biomed J Sci \& Tech Res } \\
\text { 29(3)-2020. BJSTR. MS.ID.004802. }\end{array}$ \\
\hline
\end{tabular}

\section{Opinion}

Disease caused by the Severe Acute Respiratory Syndrome Coronavirus-2 (SARS-CoV-2) called COVID-19 is spreading rapidly around the world. A definitive therapy is not available, and vaccines to prevent COVID-19 are under investigation. We suggest that for first-line treatment of COVID-19 we can learn from the experiences of transplant medicine.

After transplantation of solid organs, such as after lung-, renal, heart- or livertransplantation, patients always need lifelong immunosuppressive therapy to prevent organ rejection, in most patients this is dual or triple immunosuppression. COVID-19 poses a dilemma in Solid Organ Transplant (SOT) recipients [1]. There are no evidence-based guidelines how to deal with immunosuppression in SOT recipients with COVID-19. Among the immunosuppressive drugs, Calcineurin Inhibitors (CNIs) are extremely important in preventing rejection. CNI is a calcium-calmodulin-activated serine/ threonine-specific phosphatase. Tacrolimus and cyclosporin are well-known CNIs in transplant medicine. Inhibiting calcineurin results in blockade of the translocation of the nuclear factor of activated $\mathrm{T}$ cells from the cytosol into the nucleus, in this way interfering with the production of cytokines. The potential risks of continuing immunosuppression in COVID-19, such as increased viral replication or prolonged viral shedding, should be balanced against the benefits of preventing organ transplant rejection.

Willicombe et al. describe the favorable outcomes of 11 SOT recipients with COVID-19, who all were receiving CNIs at the time of diagnosis [1]. In the mean time, an increasing number of case reports and case studies support the hypothesis of these authors, showing relatively mild COVID-19 in patients with heart-, lung-, liver- and renal transplantation [2,3]. The majority of these patients were on CNI therapy and the dosis remained unchanged during COVID-19, showing favorable outcomes in almost all patients [2]. A beneficial role of CNI was also supported by another study in SOT recipients suffering from COVID-19 who where unter CNI treatment after SOT [4]. These findings suggest that the severity of COVID-19 is less in SOT recipients, who are on chronic dual or triple immunosuppression, compared to the general population. The role of immunosuppression by CNI in patients with COVID-19 is probably beneficial.

In Severe Acute Respiratory Syndrome (SARS), caused by another coronavirus (SARS-CoV-1), it was shown that cyclosporin suppresses replication of SARS-CoV-1 [5]. Cyclosporin is a CNI that inhibits calcineurin by binding to cellular cyclophilins (Cyps). Other coronaviruses, such as the coronavirus NL63, has been shown to be inhibited by cyclosporine A-derivatives [6]. A positive role of cyclosporine as first-line therapy has been proposed by SanchezPernaute et al [7]. Among the CNIs, also tacrolimus (FK506) is of special interest [8]. By inhibiting calcineurin, and suppressing the early phase of T-cell activation and expression of cytokines it diminishes the cellular immune response, and possibly prevents the cytokine storm in COVID-19. The studies of tacrolimus in other severe coronaviral diseases merit further investigation of tacrolimus 
in COVID-19. In SARS-CoV-1, tacrolimus has shown effectiveness in animal experiments, and in Middle Eastern Respiratory Syndrome (MERS) tacrolimus was succesfully used in some case reports.

Based on these results, and the outcomes of COVID-19 in SOT recipients on tacrolimus [2], we suggest that the answer of the question if we should leave CNIs out of the cytokine storm, should be a definite "No". We even would go a step further, and suggest tacrolimus as part of a possible treatment strategy in moderate and severe COVID-19 in the general immunocompetent population. The results of the Spanish TACROVID trial, investigating the role of tacrolimus as part of the treatment in COVID-19 in the nontransplant population may shed some light on this issue [9].

\section{Conflict of Interest}

The authors have no conflicts of interest. They equally contributed to the manuscript.

\section{Funding}

No fundings.

\section{References}

1. Willicombe M, Thomas D, Mc Adoo S (2020) COVID-19 and Calcineurin Inhibitors: Should They Get Left Out in the Storm? Journal of the American Society of Nephrology 31(6): 1145-1146.

ISSN: 2574-1241

DOI: $10.26717 /$ BJSTR.2020.29.004802

René Hage. Biomed J Sci \& Tech Res

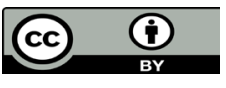

This work is licensed under Creative Commons Attribution 4.0 License

Submission Link: https://biomedres.us/submit-manuscript.php
2. Hage R, Steinack C, Benden C, Schuurmans MM (2020) COVID-19 in Patients with Solid Organ Transplantation: A Systematic Review. Transplantology 1(1): 1-15.

3. Steinack C, Hage R, Benden C, Schuurmans MM (2020) SARS-CoV-2 and Norovirus Co-Infection after Lung Transplantation. Transplantology 1(1): 16-23.

4. Cavagna L, Seminari E, Zanframundo G, Gregorini M, Di Matteo A, et al. (2020) Calcineurin Inhibitor-Based Immunosuppression and COVID-19: Results from a Multidisciplinary Cohort of Patients in Northern Italy. Microorganisms 8(7): E977.

5. Tanaka Y, Sato Y, Sasaki T (2013) Suppression of coronavirus replication by cyclophilin inhibitors. Viruses 5(5): 1250-1260.

6. Carbajo-Lozoya J, Ma-Lauer Y, Malešević M, Theuerkorn M, Kahlert $\mathrm{V}$, et al. (2014) Human coronavirus NL63 replication is cyclophilin A-dependent and inhibited by non-immunosuppressive cyclosporine A-derivatives including Alisporivir. Virus Research 184: 44-53.

7. Sanchez-Pernaute O, Romero-Bueno FI, Selva-O'Callaghan A (2020) Why Choose Cyclosporin A as First-line Therapy in COVID-19 Pneumonia. Reumatologia Clinica.

8. Hage R, Steinack C, Schuurmans MM (2020) Calcineurin inhibitors revisited: A new paradigm for COVID-19? Braz J Infect Dis. Jun 27, S1413-8670(20)30084-2. doi: 10.1016/j.bjid.2020.06.005.

9. Solanich Moreno X, et al (2020). Clinical Trial to Evaluate Methylprednisolone Pulses and Tacrolimus in Patients With COVID-19 Lung Injury (TACROVID).

$\begin{array}{ll}\text { BIOMEDICAL } & \text { Assets of Publishing with us } \\ \text { RESEARCHES } & \text { - Global archiving of articles } \\ & \text { - Immediate, unrestricted online access } \\ & \text { - Rigorous Peer Review Process } \\ & \end{array}$

